\section{Chronic Periodontitis and RANKL/OPG Ratio in Peri- Implant Mucosae Inflammation}

Lucas Carneiro Costa1, Marcos Alexandre da Fonseca ${ }^{1}$, Aristides da Rosa Pinheiro², Telma Regina da Silva Aguiar ${ }^{3}$, Aldir Nascimento Machado 2,4, Valquiria Quinelato ${ }^{1}$, Leticia Ladeira Bonato ${ }^{1}$, Diego Pinheiro Aguiar ${ }^{5}$, Thays Vieira ${ }^{6}$, Fernando Luiz Duarte de Almeida ${ }^{7}$, Julie Calixto Lobo ${ }^{6}$, Miriam Jordão $^{8}$, Priscilla Gonçalves Lomardo ${ }^{1}$, José Mauro Granjeiro ${ }^{9}$, Priscila Ladeira Casado ${ }^{1,10}$

History of chronic periodontitis (CP) is a risk factor for oseointegration failure. The osteoclastogenesis system (RANK, RANKL and OPG) is critical for bone homeostatic control. We investigated the levels of OPG and RANKL in peri-implant tissues from volunteers with and without a history of $\mathrm{CP}$ and their association with mucosae inflammation. This is a single-blind case-contro study. Diagnosis of a history of CP and peri-implant examination was performed on 46 volunteers, divided into control (without history of $\mathrm{CP}$, $n=26$ ) and $C P$ group (with history of $C P, n=20$ ). Gingival biopsies were harvested during implant exposure. Quantitative PCR evaluated OPG/RANKL mRNA expressions. OPG and RANKL proteins were analyzed by western blot and immunohistochemistry assay. The chi-square test analyzed the significance of nominal variables between groups while continuous variables were analyzed by T-test or Mann-Whitney test, after Shapiro-Wilk test evaluation. The 2- $\Delta \Delta \mathrm{CT}$ Livak method calculation evaluated the gene expression. Values of $p<0.05$ were considered statistically significant. Volunteers with CP history had 23 times higher chance of developing mucosae inflammation. High mucosae levels of RANKL $(p=0.04)$ and RANKL/OPG ( $p=0.001)$ mRNA expressions were observed in CP group. CP volunteers showed increased RANKL protein levels in opposition to decreased OPG expression. Even without active periodontitis, volunteers with a history of CP had elevated gingival levels of RANKL/OPG and higher correlation with peri-implant mucosae inflammation and implant loss.

Key Words: osteoprotegerin, RANK ligand, chronic periodontitis, mucositis, osseointegration.
'Postgraduate Program in Dentistry, UFF - Universidade Federal Fluminense, Niterói, RJ, Brazil ${ }^{2}$ Postgraduate Program in Oral Implantology, UFF - Universidade Federal Fluminense, Niterói, RJ, Brazil ${ }^{3}$ Department of Periodontology, UFF - Universidade Federal Fluminense, Niterói, RJ, Brazil ${ }^{4}$ Department of Dental Clinical, UFF - Universidade Federal Fluminense, Niterói, RJ, Brazil ${ }^{5}$ Orthopaedic and Traumatology National lnstitute, Rio de Janeiro, RJ, Brazil

${ }^{6}$ Clinical Research Unit and Biology Institute, UFF - Universidade Federal

Fluminense, Niterói, RJ, Brazil

${ }^{7}$ Implantologist in Private Practice, Rio de Janeiro, RJ, Brazil ${ }^{8}$ Department of Oral Diagnosis, UFF - Universidade Federal Fluminense, Niterói, RJ, Brazil ${ }^{9}$ National Institute of Metrology, Quality and Technology, Rio de Janeiro, RJ, Brazil and Cell Therapy Center, Clinical Research Unit and Biology Institute, UFF - Universidade Federal Fluminense, Niterói, RJ, Brazil ${ }^{10}$ Department of Periodontology, UFF - Universidade Federal Fluminense, Niterói, RJ, Brazil

Correspondence: Dra. Priscila Ladeira Casado, Rua Mário Santos Braga, 28, Centro, 24020-140 Niterói, RJ, Brazil. Tel: +55-21-2629-9920. email: plcasado@hotmail.com

\section{Introduction}

The osteogenic process requires a careful chronological coordination of molecular signals to drive proliferation, migration and differentiation of mesenchymal precursor cells in osteoblasts (1). Osseointegration success is determined by the incorporation of the woven bone and the bone mass' adaptation to bearing a load (2).

Recently, chronic periodontitis (CP) was considered a major risk factor for impaired osseointegration process $(3,4)$. Similar to periodontitis, in peri-implantitis, increased microbial activity can disrupt the balance of the host response, stimulating osteoclastic activity with consequent bone resorption and implant loss (5). Advances in bone cell biology demonstrated that bone resorption is regulated by the interplay of a cytokine system belonging to tumor necrosis factor ligand and receptor superfamilies, which comprise the osteoclastogenesis system - the receptor activator nuclear factor kappa-B (RANK)/ RANK ligand (RANKL)/osteoprotegerin (OPG) (6).

RANKL, also known as TNFSF11, is the eleventh member of the OPG ligand family, expressed by osteoblasts, stromal cells, fibroblasts, B cells and T cells when stimulated by cytokines and bacterial lipopolysaccharides (7). Its action is conducted by connecting to RANK on the surface of preosteoclast/osteoblast cells, resulting in the enhancement of osteoclasts activity (8).

Conversely, OPG, also known as osteoclastogenesis inhibitory factor or TNFRSF11B, is a soluble circulating decoy receptor of RANKL that antagonizes the RANK-RANKL interaction and, therefore, promotes bone formation by inhibiting osteoclastogenesis (9). RANKL and OPG regulate bone resorption by positive or negative stimulation of RANK on osteoclast cells (10). The positive association of genetic markers for RANK and OPG has been observed in bone-destructive diseases, such as Paget's disease, familial expansile osteolysis and osteoporosis. In addition, studies have shown that the relative ratio of RANKL/OPG is higher in sites with periodontitis when compared to healthy sites (10).

Few studies on the role of RANKL/OPG in peri-implant failure have been reported. These studies have found the 
association of higher OPG levels with healthy peri-implant status, and increased RANKL expression with peri-implant disease $(11,12)$.

As far we know, no previous study detected early peri-implant tissue alterations associated with the osteoclastogenesis system. Taking into account that: the bone remodeling process is crucial for osseointegration and peri-implant health; patients with CP history show high risk for peri-implant disease $(13,14)$ and the osteoclastogenesis system is the main pathway for osteoclastic activation, our hypothesis is that subjects with history of $\mathrm{CP}$ have high RANKL/OPG expression during osseointegration period, disrupting the peri-implant tissue's healing.

Therefore, the purpose of this study was to investigate the levels of OPG and RANKL in early osseointegrated periimplant tissues from subjects with and without a history of $\mathrm{CP}$ and its association with uneventful osseointegration and mucosae inflammation

\section{Material and Methods}

\section{Volunteers}

Forty-six volunteers, presenting 56 osseointegrated endosseous implants, were recruited for this case-control single-blind (in order to avoid any source of bias) study, from the volunteers' pool at the Dental Clinics of the Faculty of Dentistry, Universidade Federal Fluminense, Niterói, RJ, Brazil, during one year. Clinical procedures were conducted in full accordance with ethical principles, including the World Medical Association Declaration of Helsinki (version 2008) and according to recommendations from University' Research Ethics Board (Registration number 80627). Informed consent was obtained from all participants. The baseline clinical parameters for the subject population are shown in Table 1. Exclusion criteria were: biphosphonate use, intake of antibiotics and anti-inflammatory agents in the preceding three months, pregnancy and/or lactation in female volunteers, no preoperative radiography, one stage or immediate implant placement, concurrent bone grafting needed, early implant exposure during osseointegration period, non-treated periodontitis, non-compliance with study protocol and smokers. All included volunteers underwent a two-stage implant placement procedure, showing favorable bone quality and quantity (15), and had completed the recommended periodontal therapy prior implant placement. Post-operative instructions included 1 -week antimicrobial rinse ( $0.12 \%$ chlorhexidine) use and analgesics (prn). Sutures were removed at week 1 .

\section{Chronic Periodontitis Diagnosis}

The diagnosis and classification of chronic periodontitis was based on Armitage (16) including as diagnosis an adult prevalence, slow to moderate bone resorption, possible association with systemic disease and previous subgingival calculus. All diagnosis were established by a single trained and calibrated examiner. All information about the volunteer's periodontal history was obtained by accessing the individual dental records. Volunteers diagnosed with chronic periodontitis were under regular maintenance. We considered volunteers with no active periodontal disease when under clinical examination bleeding on probing and plaque accumulation were absent and no mobility was observed.

Based on periodontal status, volunteers were divided into control group (without history of chronic periodontitis, $n=26$ ) and $C P$ group (with history of chronic periodontitis, $n=20$ ).

\section{Osseointegration and Peri-Implant Mucosae Evaluation}

Implant exposure surgery was performed 3 and 6 months after implant placement for mandible and maxilla, respectively. All implants with internal hexagon and external hegan platform were placed at a crestal level, while Morse cone platform type implants were placed at the subcrestal level. The criteria for uneventful ossointegration were: implant immobility; absence of periimplant radiolucency; absence of persistent signs and/or symptoms - pain, infection, neuropathy, paresthesia, or mandibular canal commitment (17).

All peri-implant regions were underwent clinical and radiographic examination, one month after implant exposure, in order to evaluate the osseointegration and peri-implant tissue status. Clinical examination consisted of visual inspection and palpation, analysis of mucosal inflammation, edema, spontaneous bleeding, bleeding on probing, pus, implant platform type and mobility. Based on local characteristics, volunteers were characterized as (i) having uneventful healing (with adequate osseointegration, without implant mobility or mucosae inflammation) or (ii) peri-implant mucosae inflammation $(13,14)$ (with mucosae inflammation characterized by bleeding on probing and red mucosae and/or inadequate osseointegration implant mobility).

\section{RNA Expression}

Gingival biopsies were harvested from 46 volunteers (26 from control group and 20 from CP group) after the osseointegration period, during the implant exposure procedure.

Total RNA was isolated using the Trizo ${ }^{\circledR}$ Reagent (InvitrogenTM, Life Technologies, NY, USA) method according to the manufacturer's protocol. DNase treatment to digest genomic DNA was done using DNA-free DNase ${ }^{\circledR}$ (Ambion by InvitrogenTM). RNA integrity was confirmed 
on a $1.2 \%$ agarose denaturing gel electrophoresis stained with SYBR Nucleic Acid Gel Stain ${ }^{\circledR}$ (Invitrogen ${ }^{\text {TM}}{ }^{\text {). RNA purity }}$ was confirmed with the spectrophotometic absorbance ratio at 260/280 (Nanodrop ${ }^{\circledR}$ 1000, Thermo Scientific, Wilmington, DE, USA). Reverse transcription-polymerase chain reaction (RT-PCR) was performed for the synthesis of complementary DNA, from 300 ng of RNA using the system ImProm-II Reverse Transcription System $^{\text {TM }}$ (Promega Corporation,Madison, WI, USA), according to the manufacturer's protocol. The blank control (RT-PCR without RNA template) and RT (-) reactions (PCR without reverse transcription) were executed along with all RT-PCRs. The quantitative PCR (qPCR) reactions were run in the MxPro$M \times 3005 p$ software (Stratagene/Agilent Technologies, Wilmington, DE, USA) using the detection system Fast Sybr Green Master Mix (Applied Biosystems, Foster City, CA, USA) with $1.5 \mu \mathrm{L}$ of cDNA in each reaction. qPCR was performed with an activation step at $95{ }^{\circ} \mathrm{C}$ for $10 \mathrm{~min}$, followed by 40 cycles of denaturation and annealing/extension (95 ${ }^{\circ} \mathrm{C} 15 \mathrm{~s}$ and $60{ }^{\circ} \mathrm{C} 1 \mathrm{~min}$ ). It was designed specific primers for OPG (forward $5^{\prime}$ AGGAGCTGCAGTACGTCAAG $3^{\prime}$ and reverse $5^{\prime}$ TCTGGGGTTCCAGCTTGC $3^{\prime}$ ) and RANKL (5' GCAGAGAAAGCGATGGTGGA $3^{\prime}$ and 5'GGAACCAGATGGGATGTCGG 3') based on BLAST database (http://blast.ddbj.nig.ac.jp/top-j.html). A melt curve was performed for specific amplification analysis. Values were normalized with respect to constitutive expression of $\beta$-actin (forward $5^{\prime}$ - TACAATGAGCTGCGTGTGG - $3^{\prime}$ / reverse $5^{\prime}$ - AGAGGCGTACAGGGATAGCA - 3'). Data are presented as fold change relative to a calibrator (RNA pool). All reactions were performed in duplicate and checklist with essential information to ensure reproducibility (18).

\section{Western Blot}

In order to confirm gene expression results, a representative sample (eight gingival biopsies) was analyzed for OPG and RANKL proteins quantification, by mechanical and sonication process, quantified by Bradford methods (19). Five-hundred $\mu \mathrm{g}$ of protein were homogenate in sample buffer $(0.02 \mathrm{mM}$ dithioreitol; $1.38 \mathrm{mM}$ sodium dodecyl sulfate; $125 \mathrm{mM}$ Tris- $\mathrm{HCl}$, [pH 6.8 and 20\% glycerol]) and 50 $\mu \mathrm{g}$ of protein were separated by $10 \%$ SDS-polyacrylamide gel electrophoresis. Proteins were then electro-blotted to a PVDF membrane (Hy-bond TM-P, Amersham Biosciences, Brazil). Membranes were blocked in 5\% non-fat dry milk in Tris-buffered saline $0.001 \%$ Tween 20 for $1 \mathrm{~h}$ and then incubated with the primary antibodies: rabbit-polyclonal anti-OPG (Abcam, Cambridge, UK), rabbit-polyclonal anti-RANKL (Abcam) and mouse-monoclonal anti-tubulin (Clone DM1A; Sigma-Aldrich, St. Louis, MO, USA) overnight. The reaction was observed using SuperSignalWest Pico Chemiluminescent Substrate (Pierce).

\section{Immunohistochemistry}

Paraffin-embedded heads from 2 samples from both groups were sectioned in the coronal plane at $4 \mu \mathrm{m}$ thickness and mounted onto slides. Sections were dipped in xylene to remove the paraffin and dehydrated through a graded alcohol series. In order to prevent endogenous peroxidase activity, sections were incubated with $3 \%$ hydrogen peroxide in methanol for $30 \mathrm{~min}$ at room temperature following sodium citrate antigen unmasking treatment for $20 \mathrm{~min}$ at $96{ }^{\circ} \mathrm{C}$. Five percent normal goat serum in PBS-Triton (0.3\%) was used for blocking at room temperature. The following antibodies were used: anti-OPG and anti-RANKL (1:200, rabbit polyclonal antibody, Abcam) in $5 \%$ normal Bovine Serum at $5 \%$, overnight at $4{ }^{\circ} \mathrm{C}$. After that, the slides were treated with peroxidase staining (Sigma-Aldrich) and developed with diaminobezidine tetrahydrochloride (DAB-Vector Laboratories, Burlingame, CA, USA). The slides were then counterstained with Harris hematoxylin or methyl green and mounted with Entellan (Merck Millipore, São SP, Brazil) in order to visualize nuclei of the cells. Negative controls were obtained by omitting the primary antibody of each reaction. The slides were photographed under a Nikon Eclipse TE300 microscope (Nikon Company, Melville, NY, USA).

\section{Statistical Analyses}

The sample size included the spontaneous demand of patients at the Dental Clinics of the Dental School, Universidade Federal Fluminense and Universidade Veiga de Almeida over 1 year, respecting the inclusion criteria. This calculation was designed to detect a risk factor that reached $40 \%$ of the sample, with alpha of $5 \%$ and $80 \%$ power. Nominal variables were expressed as frequencies and percentages. To access the significance of nominal variables between groups, the chi-square test was performed. Continuous variables were expressed as mean and standard deviation. The Shapiro-Wilk test was used to evaluate distribution among variables. ANOVA/t-test or Mann-Whitney tests were used to compare means between groups when the variable was in a normal or non-normal distribution, respectively, including gene expression analysis after 2- $\Delta \Delta$ CT Livak method calculation. Values of $p<0.05$ were considered statistically significant. Multinomial logistic regression analyses were performed to permit the exploration of many covariates simultaneously compared to the healthy group. Statistical analyses were performed using STATA 11.1 (Stata Corp, College Station, TX, USA).

\section{Results \\ Clinical Results}

From the total of 46 volunteers evaluated during six months, there were 34 (73.9\%) women and 12 (26.1\%) men, 
with mean age $56.3 \pm 9.9$ years. No difference was found between control and CP groups regarding ethnicity, sex, age, general medical conditions and current medication. In contrast, $\mathrm{CP}$ volunteers showed higher incidence of total edentulism $(p=0.05)$ and unsatisfactory hygiene $(p=0.02)$ compared to the controls (Tables 1 and 2).

Taking into account peri-implant status (Table 3 ) one month after implant exposure, the CP group showed higher prevalence of red mucosae ( $p=0.0001)$. Twenty-four (92.3\%) volunteers in the control group showed uneventful periimplant healing during osseointegration, in contrast with $7(35 \%)$ in the CP group. Volunteers with CP history had 23 times higher chance of developing peri-implant mucosae inflammation and/or implant loss, compared to volunteers without CP history $(p<0.0001 ; 22.29$ [4.02-123.25]) (Table 4). Implant platform type had no association with impairing osseointegration.

\section{Correlation of Clinical and Osteoclastogenic Parameters}

From the total of 46 samples, OPG and RANKL mRNA were detected in 40 tissues (81.6\%). OPG showed similar $m R N A$ levels in both groups $(p=0.22)$. However, high levels of RANKL were observed ( $p=0.04)$ in the CP group. In addition, RANKL/OPG mRNA expressions showed higher association with history of $\mathrm{CP}(\mathrm{p}=0.001)$ (Fig. 1).

The initial univariate analysis demonstrated chronic periodontitis ( $p=0.0001$ ) and higher RANKL/OPG expression $(p=0.04)$ as potential predictive factors for osseointegration complications. In order to assess factors concurrently, a multivariate logistic regression was performed, showing chronic periodontitis as potential predictors associated with harmful peri-implant healing during osseointegration, characterized by peri-implant mucosae inflammation.

All mRNA and protein analyses were performed in

Table 1. Baseline characteristics of all volunteers

\begin{tabular}{lccccc}
\hline & $\begin{array}{c}\text { Total } \\
(\mathrm{n}=46)\end{array}$ & $\begin{array}{c}\text { Control } \\
(\mathrm{n}=26)\end{array}$ & $\begin{array}{c}\text { Chronic } \\
\text { periodontitis } \\
(\mathrm{n}=20)\end{array}$ & $\mathrm{p}$ value & $\begin{array}{c}\text { Odds } \\
\text { ratio (CI) }\end{array}$ \\
\cline { 2 - 5 } & $\mathrm{n}(\%)$ & $\mathrm{n}(\%)$ & $\mathrm{n}(\%)$ & & \\
\hline Ethnic group & & & & & \\
Caucasians & $26(56.5)$ & $14(53)$ & $12(60)$ & 0.92 & 1.15 \\
Non-Caucasians & $20(43.5)$ & $12(47)$ & $8(40)$ & & $0.58-2.27)$ \\
Age (years) & $56.3 \pm 9.9$ & $54.9 \pm 10.22$ & $58.1 \pm 9.5$ & 0.14 & --- \\
Sex & & & & & 1.10 \\
Female & $34(73.9)$ & $19(73.1)$ & $15(73.9)$ & & 0.84 \\
Male & $12(26.1)$ & $7(26.9)$ & $5(26.1)$ & & $(0.29-4.1)$ \\
\hline
\end{tabular}

CI: confidence interval. the same gingival sample from the same collected site. Therefore, samples obtained during implant exposure surgeries were divided in three fragments, when possible: one for RNA expression analysis, one for western blot analysis and one for immunohistochemistry. Considering the sample diameter to be about $4 \mathrm{~mm}$, just in 8 samples was possible performing western blot analysis and in 1 sample immunohistochemistry. RANKL and OPG protein levels were specifically detected in eight volunteers from the total of 49 included volunteers. The western blot analysis showed that RANKL levels were increased in CP volunteers and OPG appeared downexpressed in the same diseased volunteers (Fig. 2, columns 1-3). Therefore, we employed an affinity purified polyclonal antibody in histological sections from peri-implant tissues harvested from control and CP volunteers (Fig. 3). Lower RANKL staining in healthy subject was detected (Fig. 3A) in contrast with CP subject, who showed clearly higher detection of RANKL (Fig. 3B). Consistent OPG staining in gingiva from volunteers with history of CP (Fig 3D) was no observed. However, marked OPG staining was characteristic of gingiva from healthy volunteers (Fig. 3C).

\section{Discussion}

The purpose of this study was to investigate the levels of OPG and RANKL in healing peri-implant tissues and their association with uneventful osseointegration by comparing volunteers with and without history of $\mathrm{CP}$. The results indicated that there is significantly higher RANKL/ OPG expression in CP volunteers and it has a correlation with peri-implant mucosae inflammation. Therefore, our study supports the hypothesis that volunteers with $\mathrm{CP}$ have RANKL/OPG imbalance during osseointegration, characterized by high levels of RANKL/OPG expression, disrupting peri-implant tissue wound healing and consolidating $\mathrm{CP}$ as a risk factor for periimplant disease development.

Considerable effort has been made to understand the biological relationship between history of $\mathrm{CP}$ and peri-implant disease $(13,14,20)$. A great number of studies have focused on the osteoclastogenic system profile of chronic periodontitis $(5,6)$. However, until now, no previous study correlated OPG/RANKL levels in mucosae of volunteers with history of $\mathrm{CP}$ who underwent to implant placement and the genes' influence on the osseointegration process. According to ethical principles, this work did not collected samples from periimplant bone. All samples were collected from peri-implant mucosae which would 
be discarded during implant exposure. In addition, our research group considered, based on peri-implant anatomy, that this peri-implant mucosae represents the metabolism from bone tissue during osseointegration period.

Taking into account that the molecules responsible for the osteoclastogenic system and bone homeostasis work in a network-like organization (11), this study clearly demonstrated the relationship between $\mathrm{CP}$ and the presence of mucosae inflammation in early osseointegrated implants. The main findings of our analyses can be explored as follows: (i) the destructive tissue pattern related to exacerbated inflammatory response in volunteers with $\mathrm{CP}$ (116) remains even after tooth loss, and this exacerbated response is possibly an individual pattern related to CP's genetic basis, not just a local factor associated with the presence of infection around tooth; (ii) the relationship between high incidence of peri-implant mucosae inflammation in volunteers with $\mathrm{CP}$ has the osteoclastogenesis system as biological basis, with increased levels of osteoclast activators (RANKL) in peri-implant tissues from CP volunteers.

It's a general consensus that peri-implantitis is characterized by progressive bone destruction and it is the main cause of implant failures. However, mucosae inflammation occurs prior to irreversible peri-implant bone loss (21). Therefore, signs of inflammation were evaluated in all volunteers during clinical examination in order to indicate the possibility of complications with the osseointegration process. In our study, volunteers with CP

Table 2. Clinical findings and anamnesis data

\begin{tabular}{|c|c|c|c|c|c|}
\hline \multirow{2}{*}{ Parameters } & Total $(n=46)$ & Control $(n=26)$ & Chronic periodontitis $(n=20)$ & $\mathrm{p}$ value & Odds ratio $(\mathrm{CI})$ \\
\hline & n $(\%)$ & n (\%) & n (\%) & & \\
\hline \multicolumn{6}{|l|}{ General medical condition } \\
\hline Diabetes & $1(2.2)$ & $1(3.8)$ & 0 & 0.56 & --- \\
\hline Rheumatoid diseases & 0 & 0 & 0 & --- & --- \\
\hline Osteoporosis & $1(2.2)$ & $1(3.8)$ & 0 & 0.56 & --- \\
\hline High blood pressure & $4(8.7)$ & $3(11.5)$ & $1(5)$ & & \\
\hline Cardiovascular diseases & 0 & 0 & 0 & & \\
\hline Hypothyroidism & $1(2.2)$ & $1(3.8)$ & 0 & 0.56 & --- \\
\hline Asthma & 0 & 0 & 0 & --- & --- \\
\hline HIV & $1(2.2)$ & 0 & $1(5)$ & 0.43 & RR 2.36 (1.68-3.33) \\
\hline Hepatitis B & $1(2.2)$ & 0 & $1(5)$ & 0.43 & RR 2.36 (1.68-3.33) \\
\hline \multicolumn{6}{|l|}{ Current medication } \\
\hline Anti-hypertension & $5(10.9)$ & $3(11.5)$ & $2(10)$ & 0.62 & $0.85(0.12-5.6)$ \\
\hline Antimicrobials & 0 & 0 & 0 & --- & --- \\
\hline NSAIDst & 0 & 0 & 0 & --- & --- \\
\hline SAIDs $¥$ & 0 & 0 & 0 & --- & --- \\
\hline Hormone reposition & $3(6.5)$ & $3(11.5)$ & 0 & 0.17 & --- \\
\hline Antidepressant & $1(2.2)$ & $1(3.8)$ & 0 & 0.56 & --- \\
\hline Anti-epileptic & $1(2.2)$ & $1(3.8)$ & 0 & 0.56 & --- \\
\hline \multicolumn{6}{|l|}{ Clinical measurements } \\
\hline Total edentulism & $8(17.4)$ & $2(7.6)$ & $6(30)$ & 0.05 & $5.14(0.91-29.03)$ \\
\hline Partial edentulism & $380(82.6)$ & $24(92.3)$ & $14(70)$ & & \\
\hline \multicolumn{6}{|l|}{ Oral Hygiene } \\
\hline Satisfactory & $42(91.3)$ & $26(100)$ & $16(80)$ & \multirow{2}{*}{0.02} & --- \\
\hline Unsatisfactory & $4(8.7)$ & 0 & $4(20)$ & & --- \\
\hline
\end{tabular}

CI: confidence interval; RR: Relative risk. 
showed significant incidence of mucosae inflammation compared to volunteers without $\mathrm{CP}$ history, and 2 volunteers lost the implant. These data showed that volunteers with $\mathrm{CP}$ have 23 times higher chance of developing complications in mucosae and bone around implant, consolidating $\mathrm{CP}$ as a risk factor for peri-implantitis development.

Different mediators have been identified in the process of periodontal bone destruction, including arachidonic acid metabolites, cytokines, and nitric oxide (22). The proinflammatory cytokines, prostaglandin E2 (PGE2), IL-1b, IL-6, and TNF-a, together with a number of other mediators of bone metabolism (TGF-b, PTH, 1,25-dihydroxyvitamin D3, glucocorticoids and estrogen), exert their effects on osteoclastogenesis by regulating osteoblastic/stromal cell production of OPG and RANKL (23).

Previous studies related that the change in the levels of RANKL play a major role in the bone loss observed in periodontitis $(24,25)$. An increased concentration of RANKL and a decrease of OPG has been detected in gingival crevicular fluid (26) and gingival tissues $(24,26,27)$ from volunteers with periodontitis. Similarly, high RANKL/OPG levels were associated with peri-implant tissue destruction (11). Rakic et al. (12) emphasized the role of RANKL and $\mathrm{OPG}$ as prognostic biomarkers in peri-implantitis, suggesting that expressions of osteoclastogenesis related factors may play an important role in the onset and severity of the peri-implantitis.

Our study tried crossing two diseases with similar etiology and immunologic pattern, chronic periodontitis and peri-implant disease, specifically mucositis, based on the biology of the osteoclastogenesis system and the possible early etiology of peri-implant disease. Multivariate analysis affirmed $\mathrm{CP}$ to be associated with higher RANKL/ OPG expression and a predictive factor for peri-implant mucosae inflammation.

In order to ensure the OPG and RANKL effect on harmful peri-implant healing and implant loss, we performed Western Blot and immunohistochemical analyses. The

Table 4. Correlation between history of chronic periodontitis and peri-implant mucosae inflammation (harmful healing)

\begin{tabular}{lcccc}
\hline Group & $\begin{array}{c}\text { Uneventful } \\
\text { healing }\end{array}$ & $\begin{array}{c}\text { Harmful } \\
\text { healing }\end{array}$ & p value & Odds ratio (CI) \\
\hline $\begin{array}{l}\text { Control } \\
(\mathrm{n}=26)\end{array}$ & 24 & 2 & & \\
$\begin{array}{l}\text { Chronic } \\
\text { periodontitis } \\
(\mathrm{n}=20)\end{array}$ & 7 & 13 & & $\begin{array}{c}22.29 \\
(4.02-123.25)\end{array}$ \\
\hline
\end{tabular}

Table 3. Peri-implant status

\begin{tabular}{|c|c|c|c|c|c|}
\hline \multirow{2}{*}{ Peri-implant status } & Total $(n=46)$ & Control $(n=26)$ & Chronic periodontitis $(n=20)$ & \multirow{2}{*}{$\mathrm{p}$ value } & \multirow{2}{*}{ Odds ratio $(\mathrm{CI})$} \\
\hline & n $(\%)$ & n $(\%)$ & n $(\%)$ & & \\
\hline Spontaneous bleeding & 0 & 0 & 0 & --- & \\
\hline Bleeding on probing & $15(32.6)$ & $2(7.7)$ & $13(65)$ & $<0.0001$ & --- \\
\hline Red mucosae & $15(32.6)$ & $2(7.7)$ & $13(65)$ & 0.0001 & $37.5(4.19-335.038-78.31)$ \\
\hline Edema & $7(15.2)$ & $1(3.8)$ & $6(30)$ & 0.004 & RR 2.85 (1.87-4.35) \\
\hline Pus & $1(2.1)$ & 0 & $1(5)$ & 0.43 & RR 2.36 (1.68-3.33) \\
\hline Mobility (presence) & $2(4.3)$ & 0 & $2(10)$ & 0.18 & RR 2.44 (1.713-3.48) \\
\hline \multicolumn{6}{|l|}{ Implant region } \\
\hline Superior & $30(65.2)$ & $17(65.3)$ & $13(65)$ & \multirow[b]{2}{*}{0.77} & \multirow[b]{2}{*}{$0.99(0.28-3.34)$} \\
\hline Inferior & $16(34.8)$ & $9(34.7)$ & $7(35)$ & & \\
\hline \multicolumn{6}{|l|}{ Implant-platform type } \\
\hline $\mathrm{EH}$ & $6(13)$ & $3(11.5)$ & $3(15)$ & 0.36 & \\
\hline $\mathrm{IH}$ & $4(8.7)$ & $1(3.8)$ & $3(15)$ & & \\
\hline MC & $36(78.3)$ & $22(84.7)$ & $14(70)$ & & \\
\hline Screw exposure & $2(4.3)$ & $1(3.8)$ & $1(5)$ & 0.68 & $1.31(0.07-22.41)$ \\
\hline Peri-implant plaque & $1(2.1)$ & 0 & $1(5)$ & 0.43 & RR 2.36 (1.68-3.33) \\
\hline Implant loss & $2(4.3)$ & 0 & $2(10)$ & 0.18 & RR 2.44 (1.71-3.48) \\
\hline
\end{tabular}

CI: confidence interval; RR: Relative risk; External Hexagon (HE) Internal Hexagon (IH) Morse Cone (MC). 


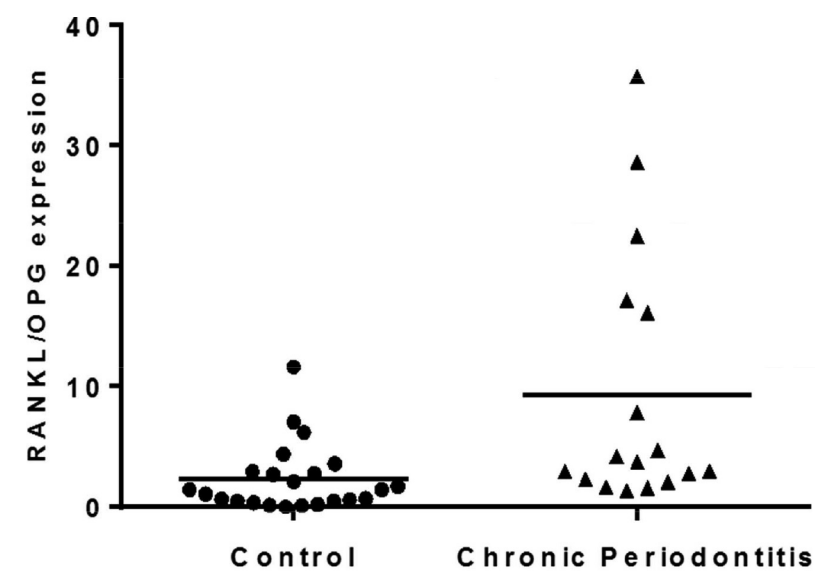

Figure 1. Messenger RNA expression levels of RANKL and OPG genes in mucosae samples. Values represent the relative expression as determined by $2-\Delta \Delta \mathrm{CT}$.

\section{Healthy}
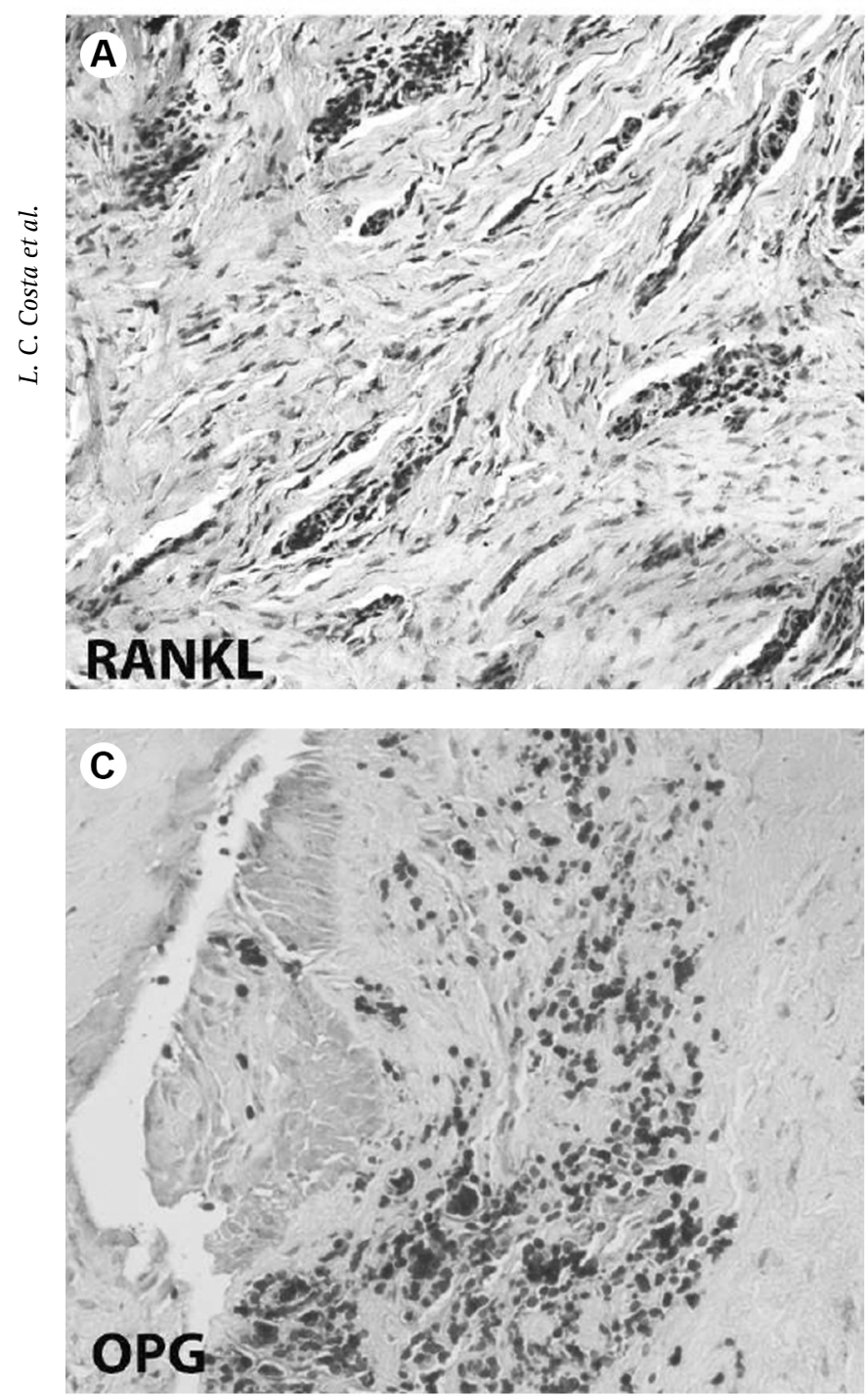

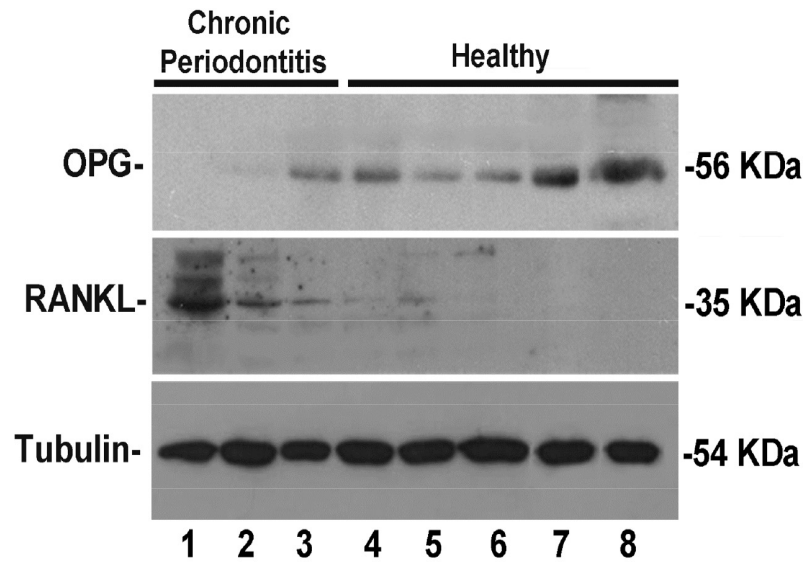

Figure 2. RANKL/OPG protein expression in Western Blot analysis from eight volunteers. Note marked expression of RANKL and downexpression of OPG in CP volunteers (Columns 1-3).
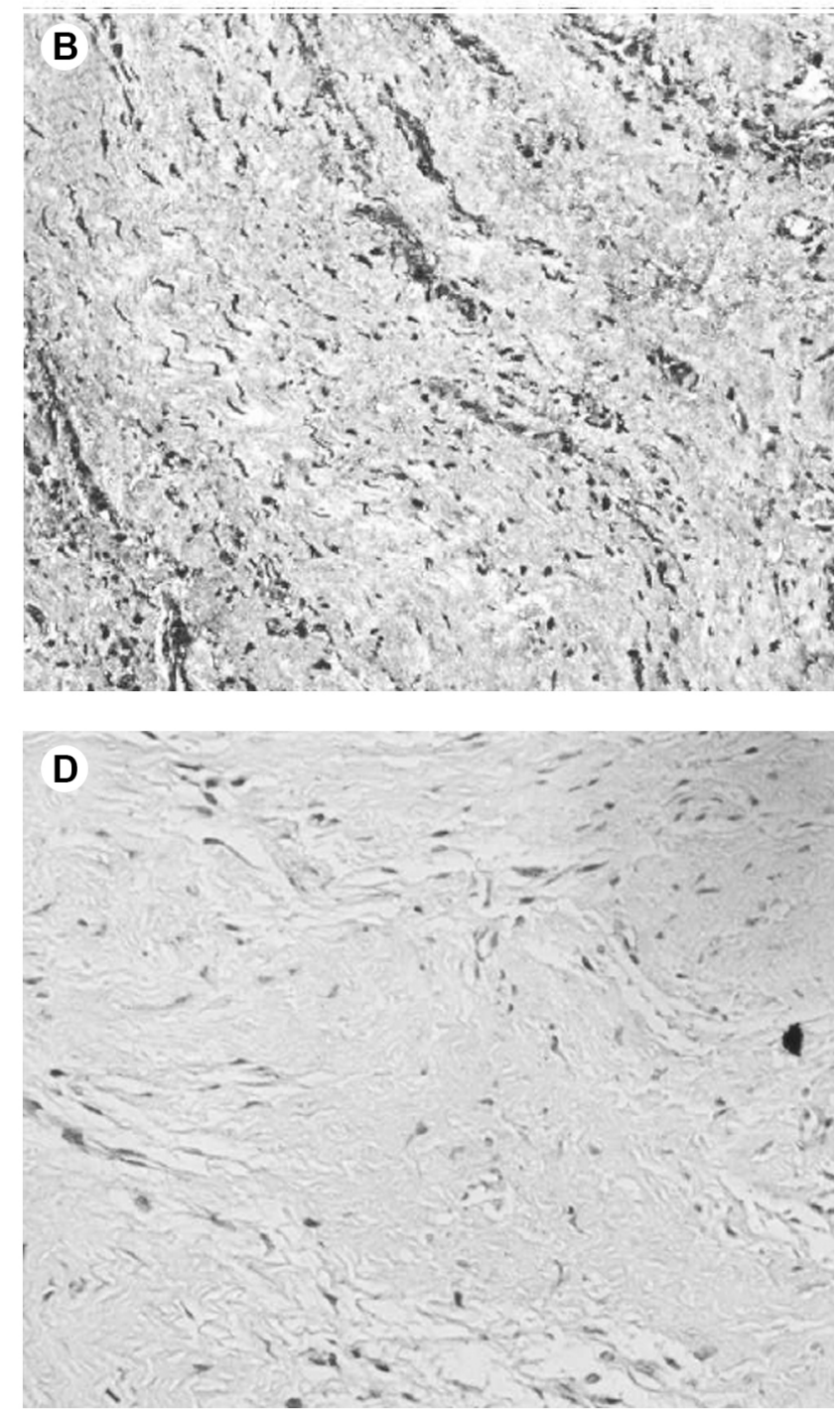

Figure 3. Immunohistochemical staining for RANKL and OPG showed marked difference between peri-implant mucosae from control and $\mathrm{CP}$ volunteers. 
exploration of the molecular mechanism of early periimplant failure was consistent with RANKL/OPG gene expression levels. RANKL protein was overexpressed in tissues from volunteers with $\mathrm{CP}$ history even without disease activity. These results corroborate with previous findings $(11,12,28)$, indicating that peri-implant complications and implant loss could be a genetic factor, and that the molecular mechanism of bone resorption can be active in volunteers with $\mathrm{CP}$ history.

Despite the fact that significant statistical difference was not found, some important variables that could influence in such results, in our research, is the difference between crestal and subcrestal implant placement, the implant position and the early implant exposure. In addition, gingiva samples were not collected at the baseline, during implant placement, becoming impossible determining the relationship between baseline levels of RANKL/OPG and its level after implant exposure.

This is the first study obtaining supporting evidence for an association between the occurrence of periimplant mucosae inflammation and history of chronic periodontitis, considering the biologic interaction in the osteoclastogenesis system. Even without active periodontitis, volunteers with a history of $\mathrm{CP}$ had elevated tissue levels of RANKL/OPG and higher correlation with peri-implant mucosae inflammation and implant loss, showing that the destructive pattern remains in the mucosa and bone of these risk volunteers. Therefore, RANKL/OPG correlation may have a potential value as a biomarker for early complications in the peri-implant tissue. Overall, we encourage future studies to identify volunteers at an increased risk for peri-implantitis. A detailed analysis of osteoclastogenesis and inflammatory biomarker mechanisms and their consequences should also be studied, and, in the long term, their effects on the osseointegration process.

\section{Resumo}

A história de periodontite crônica (CP) é um fator de risco para falhas na osseointegração. 0 sistema de osteoclastogênese (RANK, RANKL e OPG) é crucial para o controle da homeostase óssea. 0 objetivo deste estudo foi investigar os níveis de OPG e RANKL no tecido peri-implantar de voluntários com e sem histórico de CP e sua associação com inflamação da mucosa. Este é um estudo tipo caso-controle. 0 exame para diagnóstico de $\mathrm{CP}$ e na região peri-implantar foi realizado em 46 voluntários, divididos em controle (sem história $\mathrm{CP}, \mathrm{n}=26$ ) e grupo $\mathrm{CP}$ (com histórico de $C P, n=20$ ). Descartes gengivais foram obtidos durante a exposição do implante. PCR quantitativo avaliou a expressão do RNAm de OPG/ RANKL. As proteinas OPG e RANKL foram analisadas por western blot e imunohistoquimica. 0 teste do qui-quadrado analisou a significância entre as variáveis nominais enquanto as variáveis contínuas foram analisadas pelo teste-t e Mann-Whitney, após o teste de Shapiro-wilk. 0 método do Livak 2-- $\Delta \Delta C T$ avaliou a expressão gênica. Os voluntários com $\mathrm{CP}$ apresentaram 23 vezes mais chances de desenvolver inflamação da mucosa. Expressão elevada no RNAm de RANKL ( $p=0.04)$ e RANKL/ OPG $(p=0.001)$ foram observadas no grupo CP. Voluntários com CP mostraram aumento dos niveis da proteína RANKL em contraste com diminuída expressão de OPG. Mesmo sem periodontite ativa, voluntários com histórico de CP apresentaram elevado nivel gengival de RANKL/OPG e alta correlação com inflamação peri-implantar e perda do implante.

\section{References}

1. Zaidi M. Skeletal remodeling in health and disease. Nature Med 2007;13:791-801.

2. Parithimarkalaignan S, Padmanabhan TV. Osseointegration: An upadate. J Indian Protsthodontic Soc 2013;13:2-6.

3. Casado PL, Pereira MC, Duarte MEL, Granjeiro JM. History of chronic periodontitis is a high risk factor for peri-implant disease. Braz Dent J 2013;24:134-141.

4. Renvert $\mathrm{S}$, Quirynen M. Rosk indicators for peri-implantitis. A narrative review. Clin Oral Impla Res 2015;26:15-44.

5. Giannopoulou C, Martinelli-Klay CP, Lombardi T. Immunohistochemical expression of RANKL, RANK and OPG in gingival tissue of patients with periodontitis. Acta Odontol Scand 2012;70:629-734.

6. Chen B, Wu W, Sun W, Zhang Q, Yan F, Xiao Y. RANKL expression in periodontal disease: Where does RANKL come from? BioMed Res Int 2014;2014:731039.

7. Dutzan N, Gamonal J, Silva A, Sanz M, Vernal R. Over-expression of forkhead box $\mathrm{P} 3$ and its association with receptor activator of nuclear factor-kappa B ligand, interleukin (IL) -17, IL-10 and transforming growth factor-beta during the progression of chronic periodontitis. J Clin Periodontol 2009;36:396-403.

8. Cochran DL. Inflammation and bone loss in periodontal disease. J Periodontol 2008;79:1569-1576.

9. Bartold PM, Cantley MD, Haynes DR. Mechanisms and control of pathologic bone loss in periodontitis. Periodontol 2000 2010;53:55-69.

10. Kadkhodazadeh M, Ebadian AR, Gholami GA, Khosravi A, Tabari ZA. Analysis of RANKL gene polymorphism (rs9533156 and rs2277438) in Iranian patients with chronic periodontitis and periimplantitis. Arch Oral Biol 2013;58: 530-536.

11. Duarte PM, de Mendonça AC, Máximo MB, Santos VR, Bastos MF, Nociti Júnior FH. Differential cytokine expressions affect the severity of periimplant disease. Clin Oral Implant Res 2009;20:514-520.

12. Rakic M, Struillou $X$, Petkovic-Curcin A, Matic S, Canullo L, Sanz M, et al.. Estimation of bone loss biomarkers as a diagnostic tool for periImplantitis. J Periodontol 2014;30:1-12.

13. Lang NP, Berglundh T. Periimplant diseases: where are we now? Consensus of the seventh European workshop on periodontology. J Clin Periodontol 2011;38:178-181.

14. Ata-Ali J, Ata-Ali F, Bagan L. A classification proposal for periimplant mucositis and peri-implantitis: a critical update. Open Dent J 2015;9:393-395.

15. Adell R, Lekholm U, Rockler B, Brånemark PI. A 15-year study of osseointegrated implants in the treatment of edentulous jaw. Int J Oral Maxillofac Surg 1981;10:387-416.

16. Armitage GC. Periodontal diagnoses and classification of periodontal diseases. Periodontol 2000 2004;34:9-21.

17. Albrektsson TO, Johansson CB, Sennerby L. Biological aspects of implant dentistry: osseointegration. Periodontol 2000 1994;4:58-73.

18. Bustin SA, Benes V, Garson JA, Hellemans J, Huggett J, Kubista M, et al.. The MIQE guidelines: minimum information for publication of quantitative real-time PCR experiments. Clin Chem 2009;55:611-622.

19. Bradford, MM, Rapid and sensitive method for the quantitation of microgram quantities of protein utilizing the principle of protein-dye binding. Analytical Biochemistry 1976:72,248-254.

20. Casado PL, Canullo L, Filardy AA, Granjeiro JM, Barboza EP, Duarte MEL. Intreleukins 1B and 10 expressions in the periimplant crevicular fluid from patients with untreated periimplant disease. Implant Dent 2013;22:1-8.

21. Roos-Jansaker AM, Renvert S, Egelberg J. Treatment of peri-implant infections: a literature review. J Clin Periodontol 2003;30:467-485.

22. Graves D. Cytokines that promote periodontal tissue destruction. J Periodontol 2008;79:1585-1591.

23. Saika M, Inoue D, Kido S, Matsumoto T. 17beta-estradiol stimulates 
expression of osteoprotegerin by a mouse stromal cell line, ST-2, via estrogen receptor-alpha. Endocrinology 2001;142:2205-2212.

24. Crotti T, Smith MD, Hirsch R, Soukoulis S, Weedon H, Capone M, et al.. Receptor activator NF kappaB ligand (RANKL) and osteoprotegerin (OPG) protein expression in periodontitis. J Periodontal Res 2003;38:380-387.

25. Garlet G P, Martins W Jr, Fonseca BA, Ferreira BR, Silva JS. Matrix metalloproteinases, their physiological inhibitors and osteoclast factors are differentially regulated by the cytokine profile in human periodontal. J Clin Periodontol 2004;31:671-679.

26. Bostanci N, Ilgenli T, Emingil G, Afacan B, Han B, Töz $H$, et al.. Differential expression of receptor activator of nuclear factor-
kappaB ligand and osteoprotegerin mRNA in periodontal diseases. J Periodontol Res 2007;42:287-293.

27. Belibasakis GN, Meier A, Guggenheim B, Bostanci N. The RANKL-OPG system is differentially regulated by supragingival and subgingival biofilm supernatants. Cytokine 2011;55:98-103.

28. Kinane DF, Preshaw P M, Loos B G. Host-response: understanding the cellular and molecular mechanisms of host-microbial interactionsconsensus of the Seventh European Workshop on Periodontology. J Clin Periodontol 2011;38:44-48.
Received March 22, 207 Accepted July 23, 2017 